\title{
Peak Timing in Two Dialects of Connaught Irish
}

\author{
Martha Dalton and Ailbhe Ní Chasaide.
}

\author{
Phonetics and Speech Lab \\ University of Dublin, Trinity College Dublin, Ireland \\ daltonmetcd.ie, anichsidetcd.ie
}

\begin{abstract}
A comparison of the peak location in nuclear and initial prenuclear accents was carried out for two closely related dialects of Connaught Irish: Cois Fharraige and Inis Oirr. This was done across conditions where the number of unstressed syllables following the nuclear and preceding the initial prenuclear accents was varied from 2-0. Clear differences in peak timing emerged between the two dialects. In Cois Fharraige Irish the timing of the peak is unaffected by the presence and/or number of adjacent unstressed syllables. In Inis Oirr Irish there is variability in peak timing for both prenuclear and nuclear positions. In nuclear position Inis Oirr peak realizations for the different conditions range from the left edge of the accented vowel to the post accented vowel. In prenuclear position realizations range from the left-edge of the accented vowel as far as the right edge of the post accented syllable.
\end{abstract}

\section{Introduction}

This paper is concerned with cross-dialect differences in Irish intonation and looks at the alignment of high $\left(\mathrm{H}^{*}\right)$ tonal targets in two closely related dialects. The work forms part of an ongoing project on the prosody of Irish dialects [1] aimed at providing a broad account of the prosodic system of the main dialects of Irish encompassing intonation, temporal/rhythmic aspects, and to some degree, voice quality variation.

The intonational analyses are being carried out within the framework of Autosegmental-Metrical (AM) phonology [2]. One of the difficulties that arise with phonologically-based accounts of intonation is that, at the structural level, dialects can look very similar, and important differences which belong to the phonetic realizational level are necessarily obscured. While listeners are sensitive to prosodic differences among dialects, the typical linguistic descriptions rarely adequately capture these differences. In order to account for the audible differences that listeners are attuned to, we clearly need to have measures that capture these fine phonetic differences in realization.

This paper examines the hypothesis that the two dialects of Connemara - Cois Fharraige near Galway city and Inis Oirr, one of the Aran Islands (see Figure 1) - are differentiated in terms of the alignment of the melodic peak to the segmental string. The dialects in question are geographically close to each other and have been described by linguists as being effectively the one dialect $[3,4]$. The dialects in question were chosen precisely for this reason.

Research demonstrates that the time-alignment of otherwise similar "tunes" relative to the segmental string is an important dimension of cross-dialect and cross-language differentiation. Our research on Irish dialects gains impetus from and contributes to the growing pool of knowledge on prosodic typology, across and within languages (see for example $[5,6])$. It is hoped that our time alignment data will not only enable finer comparisons among the Irish dialects, but will also provide interesting points of comparison with the emerging typological body of evidence from other languages, permitting us to get a sense of how the "tunes" of Irish differ from similar tunes in other languages.

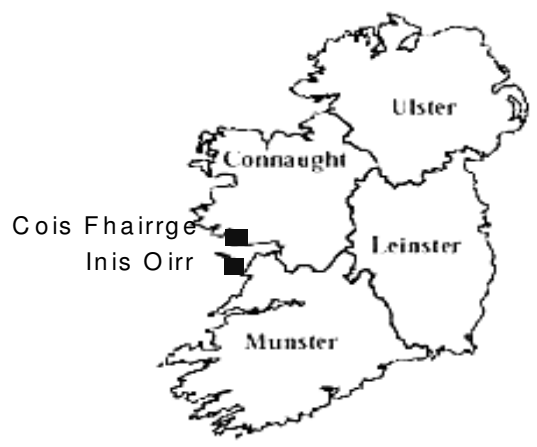

Figure 1: Map of Ireland illustrating the location of the Connaught dialects

The timing of the melodic peaks and valleys to the segmental string has been shown in other languages to vary as a function of many different factors [7]. One frequent finding is that the timing of intonational peaks tends to "drift" when the number of syllables preceding the initial prenuclear accent varies: similar drift is observed when the number of syllables following the nuclear accent varies. So for example, in English, the peak in nuclear accents drifts rightwards with an increase in the number of following syllables $[8,9]$. In prenuclear accents of English the number of preceding unstressed syllables has also been found to produce a similar effect: a leftward drift in peak timing occurs when the size of the anacrusis increases [10]. Structurally the Connaught dialects present a pattern rather like that reported for different varieties of English [e.g. 11] and therefore one would hypothesize that these dialects might be likely to conform to the more minute peak timing relationships reported for English. To test this hypothesis, the paper presents a comparison of peak timing in these two closely related dialects, for nuclear accents with differing numbers of following unstressed syllables, and for initial prenuclear accented syllables where the size of the anacrusis varies.

One further motivation of our current research should be mentioned. In a parallel activity we are hoping to develop a text-to-speech system for Irish [12]. We are thus particularly interested in providing an account of Irish intonation that can be implemented in synthesis. The focus on the finer detail of the timing of the melodic tier is crucial to this intended 
application of results.

\section{AM account of Connaught Irish}

Earlier papers [13, 14] have presented descriptions of some dialects of Irish (Connaught and Ulster). A brief summary of the main tonal patterns found in the Connaught Irish dialects is provided here.

Declarative sentences in Connaught Irish are characterized by predominantly $\mathrm{H}^{*}+\mathrm{L}$ nuclear pitch accents. Prenuclear accents are typically sequences of $\mathrm{H}^{*}$. Downstep between successive prenuclear accents is frequently present with the exception of the final nuclear accent which does not tend to be downstepped.

A typical Connaught Irish declarative would be labeled:

$$
\begin{array}{llll}
\mathrm{H}^{*} & ! \mathrm{H}^{*} & \mathrm{H}^{*}+\mathrm{L} & 0 \%
\end{array}
$$

The basic tonal pattern for wh-questions in Connaught Irish is generally similar to the declarative one. Yes/No questions differ in terms of the initial prenuclear accent which tends to be realised as a low-rising $\mathrm{L}^{*}+\mathrm{H}$ accent.

\section{Methods and Materials}

The analysis is being carried out within the framework of autosegmental-metrical phonology, using the IViE labelling system [15]. For transcription and annotation we employ the PRAAT shareware [16] which provides acoustic displays of f0, with time-aligned labelling fields.

Two speakers were recorded and analyzed for each of the Connaught dialects. The speakers were all female speakers between aged 28-55 from similar social backgrounds. None of the informants were professional speakers (actors, radio announcers etc.).

\subsection{Materials}

The test sentences for this analysis designed to elicit the stressed syllable $/ \mathrm{grb} /$ in initial prenuclear $(\mathrm{PN})$ and nuclear (N) positions. For PN the size of the anacrusis was varied from two (PN2), to one (PN1) to no (PN0) unstressed syllables. Similarly for the nuclear case the number of following unstressed syllables was varied as between two (N2), one (N1) and none (N0). Randomized lists containing 8 repetitions of each sentence were recorded by each speaker. 5 representative utterances were chosen from the 8 , which allowed for occasional errors, hesitations etc. Results presented here are thus for a total 60 utterances per dialect. The set of test sentences is illustrated in Table 1 .

\section{$\underline{\text { Prenuclear position }}$}

PNO

Gobann an sceach amach thar an mballa

Sticks the bush out over the wall

The bush is sticking out over the wall

PN1

Tá gobán ag teacht amach thar an mballa Is tradesman the bush out over the wall A tradesman is coming out over the wall
PN2

B'ag an ngobán a bhí an teach a b'fhearr At the tradesman that was the house the best The tradesman had the best house

\section{Nuclear position}

N0

$$
\begin{aligned}
& \text { Ní maith le Daidí an gob } \\
& \text { Not good with Daddy the beak } \\
& \text { Daddy doesn't like the beak }
\end{aligned}
$$

N1

Ní maith le Daidí an gobán

Not good with Daddy the tradesman

Daddy doesn't like the tradesman

N2
Ní maith le Daidí an gobadán
Not good with Daddy the sandpiper
Daddy doesn't like the sandpiper

Table 1. Test sentences elicited for both dialects. $\mathrm{PN}=$ prenuclear; $\mathrm{N}=$ nuclear. Numbers $0,1,2$ indicate the number of unstressed syllables preceding the prenuclear or following the nuclear accent.

\subsection{Measurements}

For prenuclear accents the segments of the accented syllable and of all unstressed syllables preceding the accent were segmented. The duration of each segment was then measured and averaged. For nuclear accents the accented nuclear syllable and the following two unstressed syllables in each utterance were measured. A number of points in the contour were then labeled, and their time location measured relative to the nearest segmental boundary. The labels for the measured timepoints are shown schematically in Figure 2.

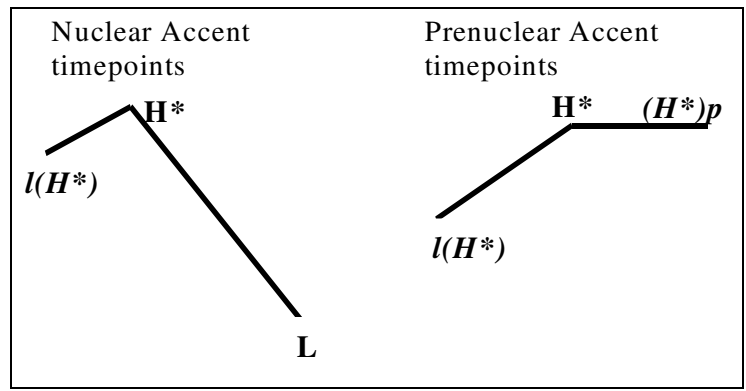

Figure 2: schematic diagram illustrating the labels associated with the timepoints measured in prenuclear and nuclear accents.

$\mathbf{H}^{*}$ represents the peak in both prenuclear and nuclear accents. $\left(\mathbf{H}^{*}\right) \mathbf{p}$ denotes end of the high plateau in the prenuclear accents. $\mathbf{L}$ represents the fo minimum corresponding to the trailing $\mathrm{L}$ tone in the $\mathrm{H}^{*}+\mathrm{L}$ nuclear accent. $\mathbf{I}\left(\mathbf{H}^{*}\right)$ represents the f0 minimum which precedes the $\mathrm{H}^{*}$ in both prenuclear and nuclear accents. 


\section{Results and Discussion}

\subsection{Prenuclear}

Results for the prenuclear conditions indicate a clear difference in peak timing for each dialect. The results are illustrated schematically in Figure 3, where they are compared to the findings reported for English. (The English data is shown by black circles, the Cois Fharraige data by grey circles and the Inis Oirr data by the white).

For the Cois Fharraige dialect the peak is stable across the three prenuclear conditions. The peak is anchored to the right edge of the accented syllable and this does not vary with a change in the size of the anacrusis. The lack of apparent shifts in the peak timing is quite striking, in comparison to results for peaks in other languages, where the number of preceding unstressed syllables does seem to have an effect (see $[10,17]$.

For Inis Oirr peak timing is more variable across the three prenuclear conditions. In PNO the peak occurs in the postaccented syllable, resulting in a delayed peak. The peak in PNO functions as a $\mathrm{H}^{*}$ accent, even though it is aligned with the following unstressed syllable, and not with the accented syllable. Where there is anacrusis, however, the peak is allowed to drift leftwards so that it occurs within the accented syllable. The leftwards drift occasioned by the presence of preceding unstressed syllables is nonetheless not correlated with the size of the anacrusis. As results for PN1 and PN2 indicate, the peak does not drift beyond the left boundary of the accented syllable and so we would hypothesize that an early peak will not occur even where there is an anacrusis greater than two. The results may suggest that the peak is preferentially anchored to the accented syllable and that the apparent rightwards drift in the case of the PNO condition might be "explained" as the exception to the rule, relating possibly to an fo rise-time requirement in absolute initial position.

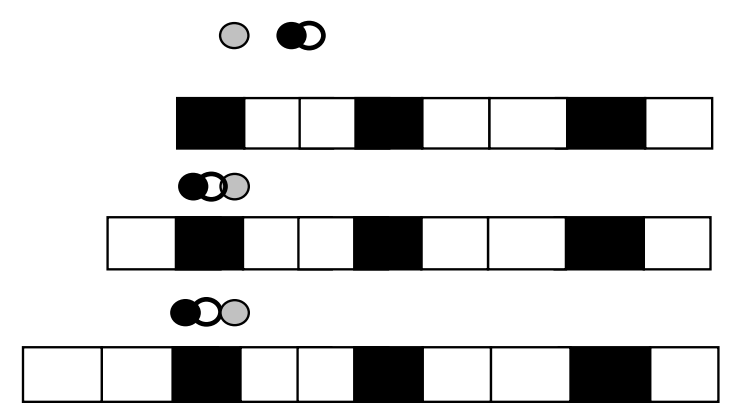

Figure 3: Schematic representation of peak locations in three prenuclear conditions for English , Cois

Fharraige $\bigcirc$ and Inis Oirr $\bigcirc$

\subsection{Nuclear}

A similar schematic representation of our results is presented in Figure 4, where they are, again, compared to findings reported for English. The Cois Fharraige nuclear accents also show a striking fixed peak location across the three nuclear conditions. $\mathrm{H}^{*}$ appears to be firmly anchored to the onset of the accented syllable: its timing does not appear to be affected by the number of following unstressed syllables. This differs from the situation reported for English [8, 9] where a rightward drift of the peak timing was found with an increase in the number of following syllables. The Cois Fharraige data is rather more similar to data reported for Northern Standard German [11] where the number of following unstressed syllables does not affect the peak location.

In comparison to Cois Fharraige, the peak timing in Inis Oirr varies relative to the segmental string, migrating rightwards (i.e. is increasingly delayed) as the number of postnuclear syllables increase. When there are no unstressed syllables following the accented syllable (N0) the peak appears to be located, as in Cois Fharraige, at the onset of the accented syllable. Where there are following unstressed syllables (N1 and N2) the peak drifts rightwards as illustrated in Figure 4.

\section{$\infty$}
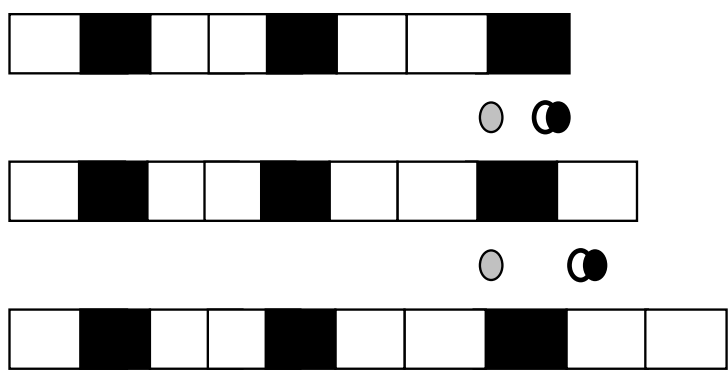

Figure 4: Schematic representation of peak locations in three nuclear conditions for English , Cois Fharraige $\bigcirc$ and Inis Oirr $\bigcirc$.

Given how very closely related these two dialects are, the results are somewhat surprising. Cois Fharraige, despite the gross structural similarity is quite strikingly different from English in these prenuclear and nuclear conditions in that the peak does not drift as a function of the number of adjacent unstressed syllables. We would therefore tend to characterize Cois Fharraige as having a fixed peak, as compared to the more variable, left and right drifting peak of Inis Oirr. Note however, that the peak in Cois Fharraige is not fixed across the different accent conditions, being right-edge aligned in the prenuclear and left-edge aligned in the nuclear conditions.

The present study is rather preliminary, being limited to two speakers per dialect, and thus conclusions must consequently be tentative. Bearing this in mind, these data do lend support to our initial hypothesis, i.e., that these dialects are differentiated in terms of peak location, and results do indicate that this measure may be an important parameter to capture the phonetic realization differences among structurally identical dialects. The difference between the two dialects of this study can be broadly characterized as a difference between a "fixed" vs. "variable" peak timing.

\section{Conclusions}

Close examination of peak timing in two very closely related dialects of Irish indicate then to be very different from each other, despite the fact that in terms of a broader phonological treatment they are structurally identical. It seems clear from the data presented here that the precise alignment of peak 
timing is likely to be a useful measure for capturing prosodic differences among even very closely related dialects, such as the two Connaught dialects analyzed here. Both dialects are differentiated in terms of peak timing. In the present data a number of clear differences emerge between nuclear and prenuclear accents. Cois Fharraige can be considered to be a "fixed" dialect. Although the $\mathrm{H}^{*}$ peak is timed differently in the nuclear and prenuclear accents, its timing remains unaffected by the presence and/or number of adjacent unstressed syllables. Inis Oirr is superficially more similar to English in that peak timing drifts for these same conditions.

Given the differences in nuclear and prenuclear accents across and within the dialects the data would suggest that nuclear and prenuclear accents should be considered as being somehow "different". This was always an assumption within the British tradition of intonational analysis, and this perspective is retained in some, though not all, AM treatments.

The data present a clear demonstration of the fine-grained differentiation among otherwise similar dialects. The fine detail of tonal alignment is highly relevant to a fundamental goal - that of understanding and being able to capture in our descriptions, the prosodic differences between dialects, and ultimately to implement these differences in synthesis

\section{Acknowledgements}

This work is supported by a Government of Ireland Senior Research Fellowship to the second author, and by the project Prosody of Irish Dialects, both of which are funded by the Irish Research Council for Research in the Humanities and Social Sciences. This work has also benefited from interactions with WISPR, an EU INTERREG IIIA Community Initiative Programme and the HUMAINE network of excellence on emotion funded by EU, Sixth Framework Programme.

\section{References}

[1] Ní Chasaide, A. Prosody of Irish Dialects: the use of intonation, rhythm, voice quality for linguistic and paralinguistic signaling. IRCHSS-funded project. www.tcd.ie/CLCS/phonetics/projects/prosody.html 20032006.

[2] Ladd, D. R. Intonational Phonology. Cambridge University Press. 1996.

[3] Ó Murchú, S. "Nótaí canúna ó Árainn, Co. na Gaillimhe", Éigse 25, 95-101, 1991.

[4] Ó Murchú, S. An Teanga Bheo: Gaeilge Chonamara. Dublin: Institiúid Teangeolaíochta Éireann, 1998.

[5] Van Leyden, K. Prosodic characteristics of Orkney and Shetland dialects: an experimental approach. Netherlands: Landelijke Onderzoekschool Taalwetenschap, 2004.

[6] Ladd, D. R., Mennen, I., \& Schepman, A. "Phonological conditioning of peak alignment in rising pitch accents in Dutch", Journal of the Acoustical Society of America, 107: 2685-2696, 2000.
[7] House, J. \& Wichmann, A. "Investigating peak timing in naturally-occurring speech: from segmental constraints to discourse structure", Speech, Hearing and Language: work in progress, 9: 99-117. UCL, 1996.

[8] Steele, J. "Nuclear accent F0 peak location: effect of rate, vowel, and number of syllables", Journal of the Acoustical Society of America, Supplement 1, 80, s51, 1986.

[9] Silverman, K. E. A., \& Pierrehumbert, J. B. "The timing of prenuclear high accents in English". In J. Kingston and M. E. Beckman (eds.), Papers in Laboratory Phonology I (pp.72-106). Cambridge University Press, 1990.

[10] Farrar, K., \& Nolan F. "Timing of F0 peaks and peak lag", Proceedings of the XIVth International Congress of Phonetic Sciences, 961-967. San Francisco. 1999.

[11] Grabe, E. Comparative Intonational Phonology: English and German. MPI Series in Psycholinguistics 7, Wageningen, Ponsen en Looien, 1998.

[12] Prys, D., Williams, B., Hicks, B., Jones, D., Ní Chasaide, A., Gobl, C., Carson-Berndsen, J., Cummins, F., Ní Chiosáin, M., Mckenna, J., Scaife, R., \& Uí Dhonnchadha, E. "WISPR: Speech processing resources for Welsh and Irish", Proceedings of the SALTMIL Workshop: First Steps in Language Documentation for Minority Languages, 68-71. LREC, Lisbon 2004.

[13] Dalton, M. and Ní Chasaide, A. "Modelling intonation in three Irish dialects" Proceedings of the XVth International Congress of Phonetic Sciences, Barcelona, 2003.

[14] Dalton, M., \& Ní Chasaide, A. "Tonal Alignment in Irish Dialects", Language and Speech: Special issue on intonation in language varieties. Kingston Press. To appear.

[15] Grabe, E., Nolan, F., \& Farrar, K. "IViE - A comparative transcription system for intonational variation in English", Proceedings of the $5^{\text {th }}$ International Conference on Spoken Language Processing, 1259-1262. Sydney, 1998.

[16] Boersma, P., \& Weenik, D. "Praat, a system for doing phonetics by the computer", Report 132. Institute of Phonetic Sciences, University of Amsterdam. 1996. www.praat.org

[17] Arvaniti, A., \& Ladd, D. R. "Tonal alignment and the representation of accentual targets", Proceedings of the XIIIth International Congress of Phonetic Sciences, 220223. Stockholm, 1995. 